\title{
Early increased density of cyclooxygenase-2 (COX-2) immunoreactive neurons in Down syndrome
}

Maria Mulet, José Miguel Blasco-Ibáñez, Carlos Crespo, Juan Nácher, Emilio Varea

Department of Cell Biology, University of Valencia, Burjassot, Spain

Folia Neuropathol 2017; 55 (2): 154-160

DOI: https://doi.org/10.5114/fn.2017.68582

\begin{abstract}
Neuroinflammation is one of the hallmarks of Alzheimer's disease. One of the enzymes involved in neuroinflammation, even in early stages of the disease, is COX-2, an inducible cyclooxygenase responsible for the generation of eicosanoids and for the generation of free radicals. Individuals with Down syndrome develop Alzheimer's disease early in life. Previous studies pointed to the possible overexpression of COX-2 and correlated it to brain regions affected by the disease. We analysed the COX-2 expression levels in individuals with Down syndrome and in young, adult and old mice of the Ts65Dn mouse model for Down syndrome. We have observed an overexpression of COX-2 in both, Down syndrome individuals and mice. Importantly, mice already presented an overexpression of COX-2 at postnatal day 30, before neurodegeneration begins; which suggests that neuroinflammation may underlie the posterior neurodegeneration observed in individuals with Down syndrome and in Ts65Dn mice and could be a factor for the premature appearance of Alzheimer's disease.
\end{abstract}

Key words: Ts65Dn, Alzheimer's disease, neuroinflammation, microglia.

\section{Introduction}

Down syndrome (DS) is the most common chromosomal aneuploidy [26]. Trisomy of chromosome 21 induces a phenotype with two hallmarks: intellectual disability and early development of Alzheimer's disease (AD) [20].

Alzheimer's disease development may be related to the presence of the amyloid precursor protein (APP) and the S100 genes on chromosome $21[1,11]$. Alzheimer's disease has been widely associated with neuroinflammation, a process that may be responsible for neuronal death observed in patients. One of the key enzymes at the top of the neuroinflammatory cascade is the COX family (cyclooxygenases) which comprises two members: COX-1 that is expressed under basal conditions and COX-2, an inducible isoform, although expressed weakly under basal conditions. Several studies have analysed the expression of COX-2 in AD brains showing contradictory effects, probably due to the different disease stages in which the studies were performed [5,35].

The Ts65Dn mouse is a DS model which is segmentally trisomic for a portion of mouse chromosome 16 and orthologous to the long arm of the human chromosome 21. This segment contains approximately 140 genes, many of which are highly conserved between mice and humans [32]. Ts65Dn mice repro- 
duce many of the alterations observed in DS, including the cholinergic degeneration present in $\mathrm{AD}$.

In this study, we aim to characterize COX-2 expression in the human temporal cortex in DS and in the Ts65Dn mouse model with age.

\section{Material and methods}

Experimental mice were generated by repeated backcrossing of Ts65Dn females to C57/6Ei $9 \mathrm{C} 3 \mathrm{H} /$ HeSnJ (B6EiC3) F1 hybrid males. The parental generation was obtained from the research colony of Jackson Laboratory. Euploid littermates of Ts65Dn mice served as controls. We used a total of 18 trisomic and 18 euploid mice in three groups: young (1 month), adult (3-4 months) and old (12-14 months). The genotypic characterization was established by qRT-PCR using SYBR Green PCR master mix (Applied Biosystems). The amount of each gene was quantified by the ABI PRISM 7700 (Applied Biosystems). The genes analysed were APP (3 copies) and Apo-B ( 2 copies) $[13,18]$. Animal experimentation was conducted in accordance with Directive 2010/63/EU of the European Parliament and Council of 22 September 2010 on the protection of animals used for scientific purposes and was approved by the Committee of Bioethics of the University of Valencia. Every effort was made to minimize the number of animals used and their suffering.

Animals were transcardially perfused under deep anaesthesia (choral hydrate 4\%, $1 \mathrm{ml} / 100 \mathrm{gr}$ bw) using $4 \%$ paraformaldehyde in phosphate buffer. Brains were cryoprotected using $30 \%$ sucrose. Fifty microns thick sections (6 subseries) were collected from each brain using a sliding freezing microtome.

Human samples were obtained from the BiOBANC HCB - IDIBAPS (Barcelona, Spain). Temporal cortex human brain tissue had been fixed ( $24 \mathrm{~h}$, paraformaldehyde $4 \%$ in buffered solution), cryoprotected (sucrose $30 \%$ ), stored at $-80^{\circ} \mathrm{C}$ and cut $(8-10 \mu \mathrm{m})$ with a cryostat. We tested 5 controls (average age 55 years old, 31-78, PMI 11 h, 7-17 h) and 5 individuals with DS (average age 53.6 years old, 36-67, PMI 11.5, 6-18 h).

\section{Single and double immunofluorescence}

Tissue was processed "free-floating" (mouse brain sections) or on slides (human sections) for immunofluorescence as follows. Sections were incubated with citrate buffer $(0.01 \mathrm{M}, \mathrm{pH}$ 6.0) for 1 minute at $100^{\circ} \mathrm{C}$. After this, sections were treated for $1 \mathrm{~h}$ with
5\% normal donkey serum (NDS) (Jackson ImmunoResearch Laboratories, West Grove, PA, USA) in PBS with $0.2 \%$ Triton-X100 (Sigma-Aldrich, St. Louis, MO, USA) and incubated overnight at room temperature either with only polyclonal goat IgG anti-COX2 (1: 500, Santa (ruz) antibody or with a mix of COX-2 antibody and one of the following antibodies: monoclonal mouse IgG anti-NeuN (1:100, Chemicon), monoclonal mouse IgG anti-Iba1 (1: 1000, Chemicon), polyclonal rabbit IgG anti-GFAP (1:1000, Sigma-Aldrich) or monoclonal mouse IgG anti-RIP (1:500, DSHB). Secondary antibodies were Alexa 488 donkey antigoat IgG (1:200 Molecular Probes) and one of the following: Alexa 555 donkey anti-mouse IgG (1:200 Molecular Probes) or Alexa 555 donkey anti-rabbit lgG (1: 200 Molecular Probes). Sections were mounted using Dako fluorescent medium (Dako North America, California). The sections were analysed using a confocal microscope (Leica TSC-SPE). Stacks (z-step $1.15 \mu \mathrm{m})$ were analysed using ImageJ software. All studied sections passed through all procedures simultaneously. All slides were coded prior to analysis until the experiment was completed.

\section{Quantification of COX-2 expression}

We analysed (1) the number of cells expressing COX-2 (high expression and low expression cells) and (2) the intensity of expression per cell in the temporal cortex of humans and mice (euploid and trisomic) of different ages. (1) For the number of cells, we counted the immunoreactive cells in 500- $\mu \mathrm{m}$-wide strips (20 strips per group) running perpendicular to the pial surface including all layers of the temporal cortex. After measuring the area, we calculated cellular density. (2) For the intensity of expression per cell, we measured the intensity of fluorescence emission in 50 cells per individual using ImageJ software. Means were determined for each experimental group and data were statistically analysed using SPSS (version 15). The difference between groups was analysed in humans with one way ANOVA (phenotype) and in mice with two way ANOVA (age and phenotype). Parallel Nissl-stained sections were used to locate the analysed region.

\section{Results}

COX-2-positive cells could be found in all layers of the temporal cortex, as well as in other cortical regions of the adult mouse. We observed COX-2 

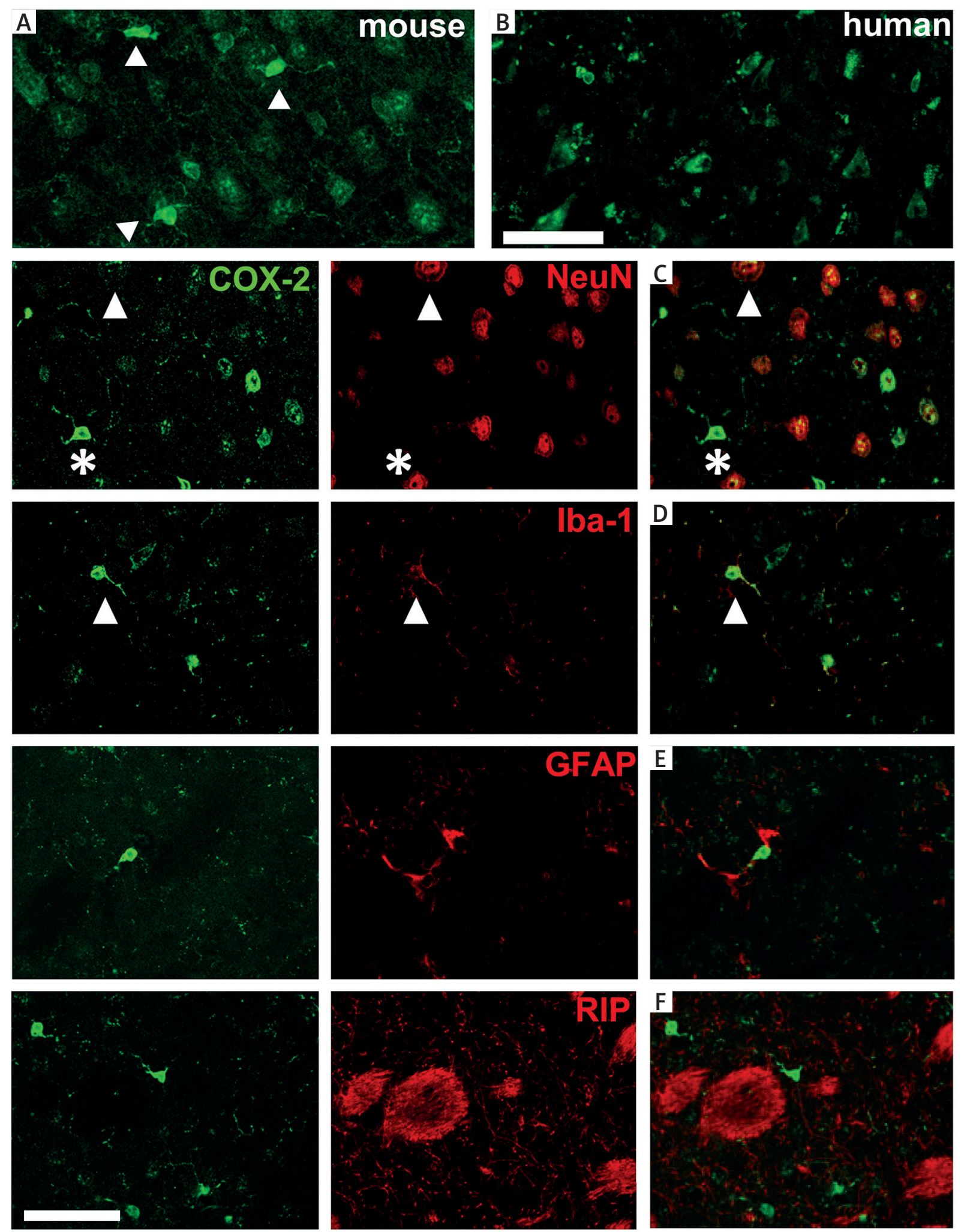

Fig. 1. COX-2 expression in mice and humans. A) Adult mouse cortex. High expression of COX-2 in small cells (arrowheads) and low expression in large cells. B) COX-2 in the human temporal cortex. C) In mice, large COX-2 expressing cells are NeuN positive (neurons, arrowheads) but small cells are not. D) COX-2 small cells are Iba-1 (microglia, arrowhead). GFAP-positive astrocytes (E) and RIP-positive oligodendrocytes (F) lack COX-2. Scale bar $50 \mu \mathrm{m}$. 
expression in two types of cells: small cells with high expression (arrowheads, Fig. 1A) and large cells with low expression (Fig. 1A). Expression of COX-2 in the temporal cortex of humans presented a similar pattern to that of mouse; however the population of small intensely stained cells was absent (Fig. 1B).

Phenotypic characterization of COX-2-expressing cells in the mouse temporal cortex reflected that the large COX-2-positive cells corresponded to neurons (NeuN positive, Fig. 1C) while the small COX-2 positive cells corresponded to microglia (Iba-1 positive, Fig. 1D). COX-2 was absent in astrocytes (GFAP, Fig. 1E) and oligodendrocytes (RIP, Fig. 1F).

Next, we studied COX-2 expression in DS individuals ( 5 controls and 5 individuals with DS) and found more COX-2-positive cells in individuals with DS $\left(428.0 \pm 29.4\right.$ cells $\left./ \mathrm{mm}^{2}\right)$ than in controls (331.0 \pm 25.4 cells $/ \mathrm{mm}^{2}, p<0.05$ ) (Fig. $2 \mathrm{~A}$ ). Analysis of the intensity of COX-2 expression in both, control and DS individuals, showed that it was similar in the positive cells in the two groups (Fig. 2B).

In the second part of the study we set out to study whether the increase in COX-2-positive cell number observed in humans was present in the temporal cortex of the mouse model for DS Ts65Dn and if so, to determine the time point of onset of the overexpression of this molecule. As shown above, there are two populations of cells in mice (Fig. 1B): small, high COX-2-expressing cells (microglia) and large, low COX-2-expressing cells (neurons) in young (1 month), adult (4 months) and old (12-14 months) mice. Analysis of the microglial cells expressing COX-2 (Fig. 3A) revealed a phenotype-dependent decrease $(p<0.05)$. Moreover, the number of microglial cells expressing COX-2 was reduced with age (young-adult $p<0.001$, and adult-old $p<0.05)$. Young: control $122.0 \pm 11.2$ vs. trisomic $94.4 \pm 4.1$ cells $/ \mathrm{mm}^{2}$; adults: control 70.3 \pm 3.0 vs. trisomic $62.5 \pm 7.9$ cells $/ \mathrm{mm}^{2}$; old: control $48.9 \pm 10.6$ vs. trisomic $38.4 \pm 10.8$ cells $/ \mathrm{mm}^{2}$. Analysis of the number of neurons expressing COX-2 in mice (Fig. 3B) (similar population as observed in humans) showed that the COX-2 neuronal density was not altered between age groups, but similar to humans, we found more COX-2-expressing neurons in trisomic mice ( $p<0.001$; Fig. 3B). Control: young $696.9 \pm$ 20.1; adult $680.3 \pm 25.2$; old $669.7 \pm 22.4$ cells $/ \mathrm{mm}^{2}$; trisomic: young $843.9 \pm 25.7$; adult $836.4 \pm 30.5$; old $824.2 \pm 58.2$ cells $/ \mathrm{mm}^{2}$. Finally we analysed the intensity of COX-2 expression in the cytoplasm of neurons (Fig. 3C) in the different groups of mice. We observed a decrease in the intensity related to age, however, similar to our findings in humans, there was no difference in the intensity of expression of COX-2 between control and trisomic mice at any age studied.

\section{Discussion}

In conclusion, we have found an increased number of COX-2 immunoreactive cells in the human DS temporal cortex as well as in the brain of the mouse model for DS (Ts65Dn) at any age examined. Our findings in humans confirm previous studies where an increased expression of COX-2 has been observed in other brain regions [24].
A

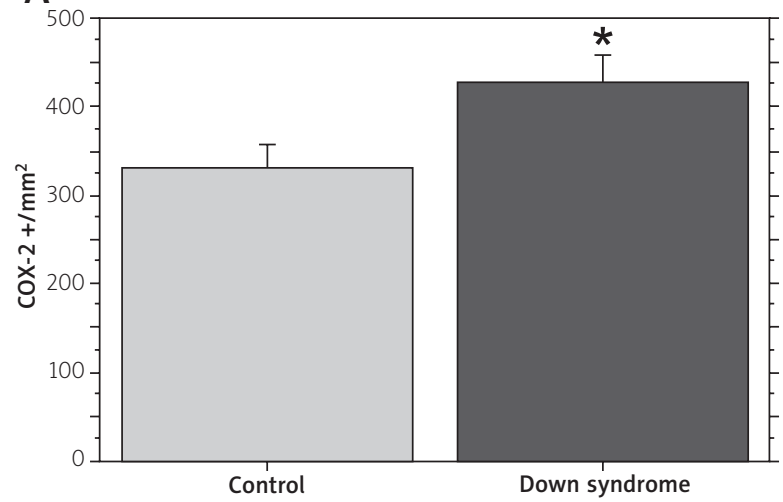

B

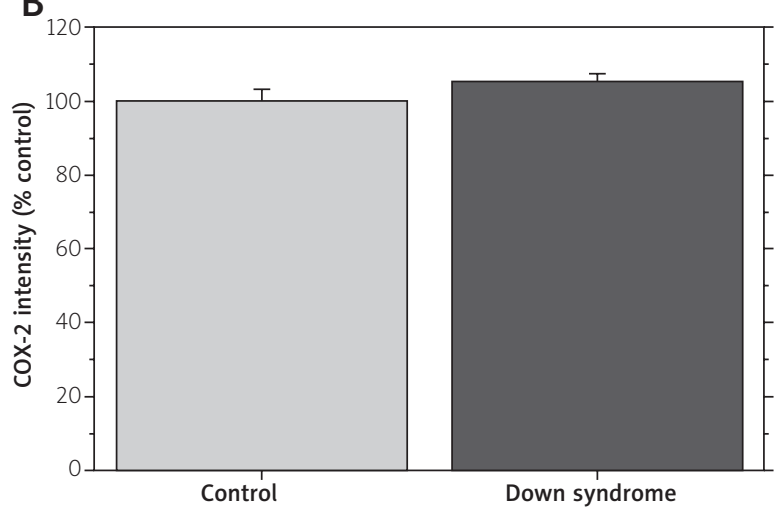

Fig. 2. Alterations in COX-2 expression in the human temporal cortex in DS. A) COX-2 cell density in the human temporal cortex (control vs. DS). B) Intensity of expression of COX-2 in the cytoplasm of neurons in the human temporal cortex (control vs. DS), values are represented in \%, being 100 in control conditions $\left({ }^{\star} p<0.05\right)$. 
A

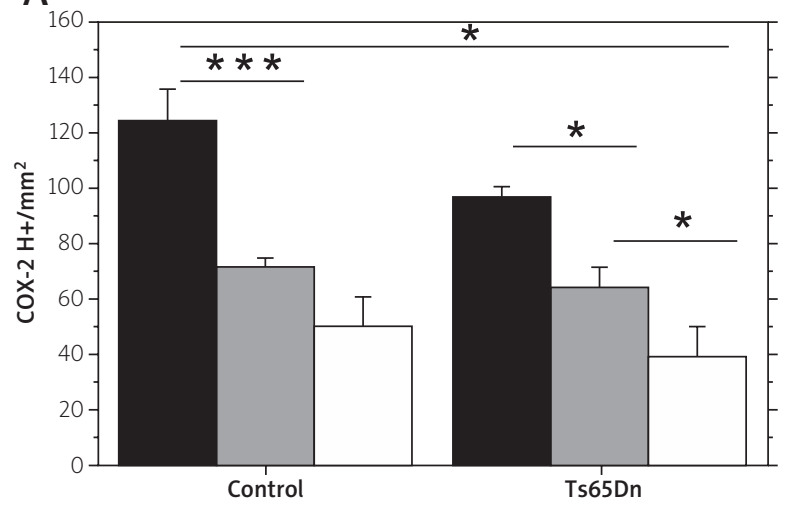

C

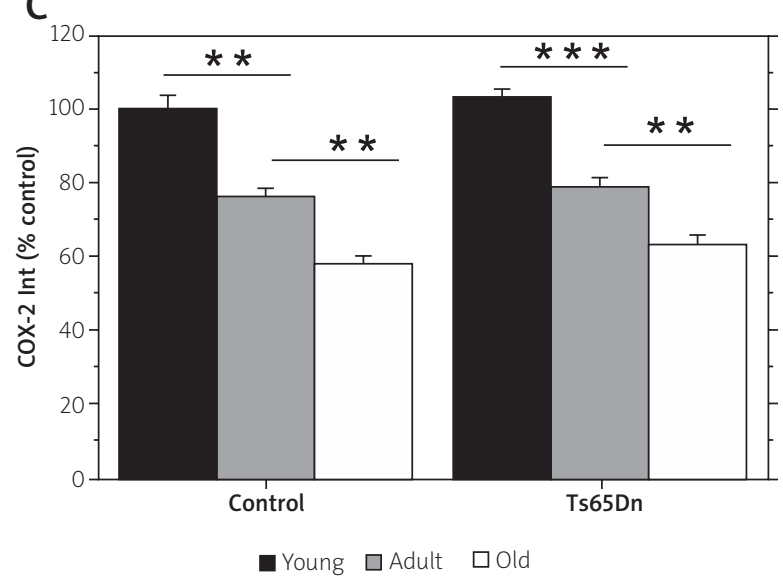

In mice it has been shown previously that COX-2 is present in neurons [16,35], although some studies found it in microglia [4,34], and even astrocytes [14]. Using an antibody previously tested in humans, we and others have shown that in humans COX-2-positive cells are always neurons [22]. However, in the mouse temporal cortex we found, in addition to large COX-2-expressing NeuN-positive cells (neurons, Fig. 1C), small COX-2-expressing cells which were Iba-1-positive and therefore microglia (Fig. 1D). COX-2 was absent in astrocytes (GFAP, Fig. 1E) and oligodendrocytes (RIP, Fig. 1F). Here we show that in the Ts65Dn mouse model, the increased number of COX-2-expressing neurons in DS is independent of age. The principal observation of our study is that this alteration starts early in DS, even in young animals (1 month old). This fact opens the possibility that, given that the alteration in COX-2 is previous to any deleterious observation, perhaps the degeneration observed in DS could be related to the alterations observed in markers such as COX-2.

The mechanism underlying the overexpression of COX-2 in DS has not been elucidated. One possibility

\section{B}

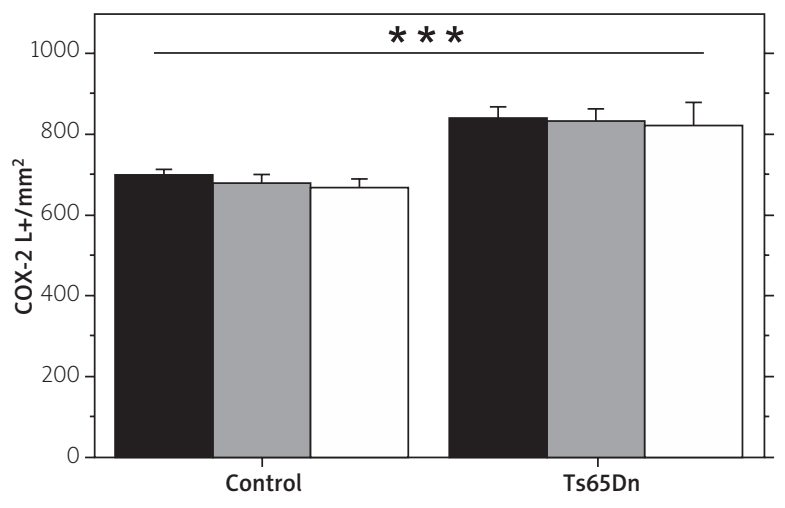

Fig. 3. Alterations in COX-2 expression in the Ts65Dn temporal cortex, changes with age. A) Change in the density of COX-2 positive microglia in the temporal cortex in control and trisomic mice at different ages. B) Change in the density of COX-2 positive neurons in the temporal cortex in control and trisomic mice with age. C) Intensity of expression of COX-2 in the cytoplasm of neurons in the mouse temporal cortex (control vs. Ts65Dn), values are represented in \%, being 100 in young control conditions $\left({ }^{*} p<0.05\right.$, $\left.{ }^{* *} p<0.01,{ }^{* * *} p<0.001\right)$.

is that the higher expression of COX-2 may be related to an extra copy of S100B present in individuals with DS [4]. S100B induces the expression of NF-KB, which is responsible, in turn, for COX-2 transcription.

Overexpression of COX-2 seems to be beneficial in the short run [9]. However, a chronic expression may be deleterious for the brain. In our animals, the density of COX-2 neurons remains unaltered with age, although some studies in old animals reported an increase with age [17]. Perhaps the reduced expression observed in the cytoplasm of old neurons in control and Ts65Dn mice, could lead to an underestimation of the number of positive cells in old animals.

Control of COX-2 expression is fundamental because of the reaction products of COX-2, proinflammatory prostanoids and reactive oxygen species, may be cytotoxic and cause CNS injury [29]. However the clear role of COX-2 in the neuroinflammatory process is still a matter of controversy (for a review, see [31]). COX-2 shows a low expression under basal conditions, but is increased during inflammatory responses and can be induced by cytokines and tumour necrosis factor [33]. Pathol- 
ogies are AD [23] or epilepsy [27] course with an increment in COX-2. Both pathologies present a high prevalence in DS individuals [20,30]. Moreover, DS is a syndrome that induces a premature ageing process. Human fibroblasts of individuals with DS show an excess of COX-2, and, when submitted to pro-inflammatory treatment, respond strongly by increasing COX-2 expression [24]. The elevated expression of COX-2 in DS could underlie, at least in part, the observed neurodegeneration in this syndrome and could explain the early onset of AD.

COX-2 has been related to adult neurogenesis and neuronal function. The KO mice for COX-2 display a reduction in hippocampal neurogenesis [21], moreover the treatment with COX-2 blockers reduces neurogenesis [8] and impairs the formation of LTP [6]. Even animal models for diabetes display parallel alterations in COX-2 expression and neurogenesis [15]. However, other studies have observed that the increased expression of COX-2 reduced the survival of the newborn cells. [2]. However, the model for DS Ts65Dn, showing an increased expression of COX-2 display a reduction in neurogenesis in the hippocampus $[7,19]$.

This apparent discrepancy could be explained attending to three main facts: (a) the analysis of the increased expression of COX-2 observed in the hippocampus of some animal models of insult, such ischemia, which induces an increase in the expression of COX-2 and neurogenesis reflects that the phenotype of the newly generated cells are mainly glia cells [28]; (b) the second possibility is related to the excess of cellular activity observed in DS [10] as well in the Ts65Dn model (Carbonell in preparation), this overactivation could be the basis of the increased expression of COX- 2 and (c) the dysregulation observed in the balance between excitation and inhibition observed in DS $[3,12,25]$. This dysregulation leads to an increase in some inhibitory neurons, including the so-called IS cells [12,13], which inhibits other inhibitory neurons generating an over-activation that is related with the high prevalence of epilepsy in individuals with DS [30] and could be related to the increased expression of COX-2 observed in neurons in the Ts65Dn model.

\section{Acknowledgments}

This study was supported by the Jerome Lejeune Foundation.

\section{Disclosure}

Authors report no conflict of interest.

\section{References}

1. Antonarakis SE, Lyle R, Dermitzakis ET, Reymond A, Deutsch S. Chromosome 21 and down syndrome: from genomics to pathophysiology. Nat Rev Genet 2004; 5: 725-738.

2. Bastos GN, Moriya T, Inui F, Katura T, Nakahata N. Involvement of cyclooxygenase-2 in lipopolysaccharide-induced impairment of the newborn cell survival in the adult mouse dentate gyrus. Neuroscience 2008; 155: 454-462.

3. Belichenko PV, Kleschevnikov AM, Masliah E, Wu C, TakimotoKimura R, Salehi A, Mobley WC. Excitatory-inhibitory relationship in the fascia dentata in the Ts65Dn mouse model of down syndrome. J Comp Neurol 2009; 512: 453-466.

4. Bianchi R, Adami C, Giambanco I, Donato R. S100B binding to RAGE in microglia stimulates COX-2 expression. J Leukoc Biol 2007; 81: 108-118.

5. Chang JW, Coleman PD, O'Banion MK. Prostaglandin G/H synthase-2 (cyclooxygenase-2) mRNA expression is decreased in Alzheimer's disease. Neurobiol Aging 1996; 17: 801-808.

6. Chen C, Magee JC, Bazan NG. Cyclooxygenase-2 regulates prostaglandin E2 signaling in hippocampal long-term synaptic plasticity. J Neurophysiol 2002; 87: 2851-2857.

7. Clark S, Schwalbe J, Stasko MR, Yarowsky PJ, Costa ACS. Fluoxetine rescues deficient neurogenesis in hippocampus of the Ts65Dn mouse model for Down syndrome. Exp Neurol 2006; 200: 256-261.

8. Goncalves MB, Williams E-J, Yip P, Yáñez-Muñoz RJ, Williams G, Doherty P. The COX-2 inhibitors, meloxicam and nimesulide, suppress neurogenesis in the adult mouse brain. Br J Pharmacol 2010; 159: 1118-1125.

9. Gopez JJ, Yue H, Vasudevan R, Malik AS, Fogelsanger LN, Lewis S, Panikashvili D, Shohami E, Jansen SA, Narayan RK, Strauss KI. Cyclooxygenase-2-specific inhibitor improves functional outcomes, provides neuroprotection, and reduces inflammation in a rat model of traumatic brain injury. Neurosurgery 2005; 56: 590-604.

10. Greber-Platzer S, Balcz B, Cairns N, Lubec G. c-fos expression in brains of patients with Down syndrome. J Neural Transm Suppl 1999; 57: 75-85.

11. Helguera P, Pelsman A, Pigino G, Wolvetang E, Head E, Busciglio J. ets-2 promotes the activation of a mitochondrial death pathway in Down's syndrome neurons. J Neurosci 2005; 25: 2295-2303.

12. Hernández-González S, Ballestín R, López-Hidalgo R, GilabertJuan J, Blasco-Ibáñez JM, Crespo C, Nácher J, Varea E. Altered distribution of hippocampal interneurons in the murine Down Syndrome model Ts65Dn. Neurochem Res 2015; 40: 151-164.

13. Hernández S, Gilabert-Juan J, Blasco-Ibáñez JM, Crespo C, Nácher J, Varea E. Altered expression of neuropeptides in the primary somatosensory cortex of the Down syndrome model Ts65Dn. Neuropeptides 2012; 46: 29-37.

14. Hirst WD, Young KA, Newton R, Allport VC, Marriott DR, Wilkin GP. Expression of COX-2 by normal and reactive astrocytes in the adult rat central nervous system. Mol Cell Neurosci 1999; 13: 57-68. 
15. Hwang IK, Yi SS, Yoo K-Y, Park OK, Yan B, Kim IY, Kim YN, Song W, Moon SM, Won M-H, Seong JK, Yoon YS. Effects of treadmill exercise on cyclooxygenase-2 in the hippocampus in type 2 diabetic rats: Correlation with the neuroblasts. Brain Res 2010; 1341 84-92.

16. Kaufmann WE, Worley PF, Pegg J, Bremer M, Isakson P. COX-2, a synaptically induced enzyme, is expressed by excitatory neurons at postsynaptic sites in rat cerebral cortex. Proc Natl Acad Sci U S A 1996; 93: 2317-2321.

17. Lee CH, Yoo K-Y, Choi JH, Park OK, Hwang IK, Kang I-J, Won M-H. Cyclooxygenase-2 immunoreactivity and protein level in the gerbil hippocampus during normal aging. Neurochem Res 2010; 35: 99-106.

18. Liu DP, Schmidt C, Billings T, Davisson MT. Quantitative PCR genotyping assay for the Ts65Dn mouse model of Down syndrome. Biotechniques 2003; 35: 1170-1174, 1176, 1178 passim.

19. López-Hidalgo R, Ballestín R, Vega J, Blasco-Ibáñez JM, Crespo C, Gilabert-Juan J, Nácher J, Varea E. Hypocellularity in the Murine Model for Down Syndrome Ts65Dn Is Not Affected by Adult Neurogenesis. Front Neurosci 2016; 10: 75.

20. Lott IT, Head E. Alzheimer disease and Down syndrome: factors in pathogenesis. Neurobiol Aging 2005; 26: 383-389.

21. Nam SM, Kim JW, Yoo DY, Choi JH, Kim W, Jung HY, Won M-H, Hwang IK, Seong JK, Yoon YS. Effects of Treadmill Exercise on Neural Stem Cells, Cell Proliferation, and Neuroblast Differentiation in the Subgranular Zone of the Dentate Gyrus in Cyclooxygenase-2 Knockout Mice. Neurochem Res 2013; 38: 2559 2569.

22. Neri M, Cantatore S, Pomara C, Riezzo I, Bello S, Turillazzi E, Fineschi $V$. Immunohistochemical expression of proinflammatory cytokines IL-1 $\beta$, IL-6, TNF- $\alpha$ and involvement of COX-2, quantitatively confirmed by Western blot analysis, in Wernicke's encephalopathy. Pathol Res Pract 2011; 207: 652-658.

23. Oka A, Takashima S. Induction of cyclo-oxygenase 2 in brains of patients with Down's syndrome and dementia of Alzheimer type: specific localization in affected neurones and axons. Neuroreport 1997; 8: 1161-1164.

24. Otsuka Y, Ito M, Yamaguchi M, Saito S, Uesu K, Kasai K, Abiko Y, Mega J. Enhancement of lipopolysaccharide-stimulated cyclooxygenase-2 mRNA expression and prostaglandin E2 production in gingival fibroblasts from individuals with Down syndrome. Mech Ageing Dev 2002; 123: 663-674

25. Pérez-Cremades D, Hernández S, Blasco-Ibáñez JM, Crespo C, Nacher J, Varea E. Alteration of inhibitory circuits in the somatosensory cortex of Ts65Dn mice, a model for Down's syndrome. J Neural Transm 2010; 117: 445-455.

26. Roizen NJ, Patterson D. Down's syndrome. Lancet 2003; 361: 1281-1289.

27. Rojas A, Jiang J, Ganesh T, Yang M-S, Lelutiu N, Gueorguieva P, Dingledine R. Cyclooxygenase-2 in epilepsy. Epilepsia 2014; 55 17-25.

28. Sasaki T, Kitagawa K, Sugiura S, Omura-Matsuoka E, Tanaka S, Yagita Y, Okano H, Matsumoto M, Hori M. Implication of cyclooxygenase-2 on enhanced proliferation of neural progenitor cells in the adult mouse hippocampus after ischemia. J Neurosci Res 2003; 72: 461-471.
29. Seibert K, Masferrer J, Zhang Y, Gregory S, Olson G, Hauser S, Leahy K, Perkins W, Isakson P. Mediation of inflammation by cyclooxygenase-2. Agents Actions Suppl 1995; 46: 41-50.

30. Stafstrom CE. Epilepsy in Down syndrome: clinical aspects and possible mechanisms. Am J Ment Retard 1993; 98 Suppl: 12-26.

31. Strauss Kl. Antiinflammatory and neuroprotective actions of COX2 inhibitors in the injured brain. Brain Behav Immun 2008; 22: $285-298$.

32. Sturgeon X, Gardiner KJ. Transcript catalogs of human chromosome 21 and orthologous chimpanzee and mouse regions. Mamm Genome 2011; 22: 261-271.

33. Vane JR, Bakhle YS, Botting RM. Cyclooxygenases 1 and 2. Annu Rev Pharmacol Toxicol 1998; 38: 97-120.

34. Villa V, Thellung S, Corsaro A, Novelli F, Tasso B, ColucciD’Amato L, Gatta E, Tonelli M, Florio T. Celecoxib Inhibits Prion Protein 90-231-Mediated Pro-inflammatory Responses in Microglial Cells. Mol Neurobiol 2016; 53: 57-72.

35. Yasojima K, Schwab C, McGeer EG, McGeer PL. Distribution of cyclooxygenase- 1 and cyclooxygenase- 2 mRNAs and proteins in human brain and peripheral organs. Brain Res 1999; 830 : 226-236. 